\title{
Secretory leukocyte protease inhibitor is associated with MMP-2 and MMP-9 to promote migration and invasion in SNU638 gastric cancer cells
}

\author{
BAIK-DONG CHOI $^{1 *}$, SOON-JEONG JEONG ${ }^{1 *}$, GUANLIN WANG ${ }^{1}$, JIN-JU PARK ${ }^{1}$, DO-SEON LIM ${ }^{2}$, \\ BYUNG-HOON KIM ${ }^{3}$, YONG-ICK CHO ${ }^{4}$, CHANG-SEOK KIM ${ }^{5}$ and MOON-JIN JEONG ${ }^{1}$ \\ ${ }^{1}$ Department of Oral Histology and Developmental Biology, Chosun University, Gwangju 501-759; \\ ${ }^{2}$ Department of Dental Hygiene, Eulji University, Gyeonggi-do 461-713; ${ }^{3}$ Department of Dental \\ Materials, School of Dentistry, Chosun University, Gwangju 501-759; ${ }^{4}$ Photonics Technology Institute, \\ Gwangju 500-779; ${ }^{5}$ Health Promotion Center, Busan Bumin Hospital, Busan 616-819, Republic of Korea
}

Received March 16, 2011; Accepted May 13, 2011

DOI: $10.3892 / \mathrm{ijmm} .2011 .726$

\begin{abstract}
Secretory leukocyte protease inhibitor (SLPI) protects tissue from proteases, and promotes cell proliferation and healing during inflammatory response. SLPI is also overexpressed in gastric, lung and ovarian cancers, which accelerates the metastasis of cancer cells. Matrix metalloproteinases-2, -9 (MMP-2 and MMP-9) are overexpressed in high metastatic cancers, and promote the migration of cancer cells through collagen degradation. SLPI and MMP-2, -9 are critical factors in stimulating the metastatic processes but there are no reports of a direct correlation between these molecules. Therefore, this study examined the role of SLPI related to MMP-2 and MMP-9 using two gastric cancer cell lines, such as characterized non-metastatic SNU484 and highly metastatic SNU638 cells. SLPI, MMP-2 and MMP-9 mRNA and protein expression were higher in SNU638 cells than in SNU484 cells. In addition, the rate of cell migration and invasion was higher in the SNU638 cells than in SNU484 cells. Interestingly, after treatment with SLPI, the rate of migration and invasion was higher in the SNU484 cells than in the positive control (PC) SNU484 cells. The rate of migration was also higher in the SNU638 cells after SLPI treatment than in the SNU638 cells (PC) but the invasion rate was not changed. The expression and secretion of MMP-2 and MMP-9 as well the rate of cell migration and invasion were significantly lower in SLPIsiRNA transfected SNU638 cells (si-SLPI/SNU638) but higher in SLPI-treated SNU484 cells (SNU484 + SLPI). Strong Elk-1 phosphorylation was detected in SNU484 + SLPI and SNU638 cells but was barely detectable in SNU484 and si-SLPI/SNU638 cells. These results show that SLPI promotes the metastasis of
\end{abstract}

Correspondence to: Professor Moon-Jin Jeong, Department of Oral Histology and Developmental Biology, School of Dentistry, Chosun University, 375 Seo-suk dong, Gwangju, Republic of Korea

E-mail: mjjeong@chosun.ac.kr

*Contributed equally

Key words: SLPI, invasion, MMP-2, MMP-9, Elk-1, gastric cancer cell
SNU638 gastric cancer cells by increasing MMP-2 and MMP-9 expression through Elk-1 signaling, indicating its role as a signaling molecule not a protease inhibitor.

\section{Introduction}

The metastatic cascade of cancer cells is viewed as a series of sequential and interrelated steps, which include the following: epithelial-mesenchymal transition (EMT), degradation of the basement membrane; dissociation of tumor cells from the primary site; invasion of the neighboring tissue; intravasation into the blood and lymph vessels; transport through the vessels; extravasation from the vessels; and proliferation at a distant site. Among these processes, tumor cells invading the neighboring tissue after degrading the basement membrane is a major development (1).

Secretory leukocyte protease inhibitor (SLPI) is an $11.7-\mathrm{kDa}$ cystein-rich protein and an epithelial cell product found in saliva, seminal plasma and in the cervical, nasal, and bronchial mucus. SLPI inhibits the serine protease activity, such as chymotrypsin, trypsin, pancreatic elastase, cathepsin G, mast cell chymase (2). Recently, SLPI was reported to be an anti-inflammatory factor that contributes at the early inflammatory response in odontoblasts (3). In addition, SLPI was reported to play a role not only in protecting the tissues from the protease (4) but also in promoting wound healing, cell proliferation, inhibiting HIV infections, anti-bacterial and anti-fungal activity $(5,6)$. The overexpression of SLPI was reported to promote metastasis in lung carcinoma $3 \mathrm{LL}-\mathrm{S}$ cells and oral carcinoma $\mathrm{KB}$ cells $(7,8)$.

Matrix metalloproteinases (MMPs) play important roles in normal physiological processes, such as embryogenesis, tissue remodeling and wound healing. The overexpression of MMPs is associated with many pathological abnormalities, such as atherosclerosis, tumor invasion and arthritic diseases (9). In overexpressed tumor cells, MMPs play a role in reorganizing the extracellular matrix through degradation as a protease (10). Among these MMPs, MMP-2 stimulates the migration of tumor cells and peripheral angiogenesis through the degradation of type IV collagen (11). The secretion of MMP-9 is high in cancers 
with a high capacity of intravasation into the blood vessels, such as breast cancer, prostatic cancer and fibrosarcoma cells (12). The inhibition of MMP-9 expression was reported to decrease the number of metastatic cancer cells in the lung (13).

The secretion of MMP-9 was low in the cells treated with SLPI, which is similar to the control, and was increased significantly in the cells treated with lipopolysaccharide (LPS) in monocytes. On the other hand, MMP-9 is suppressed in LPS treated monocytes through the addition of SLPI in a dosedependent manner (14). The secretion of MMP-2 and MMP-9 in the skin wound tissue of SLPI null mice was higher than that in normal mice (15). The migration and invasion rate in the AZ521 gastric cancer cell line was increased strongly by the overexpression of SLPI (16). MMP-2 and MMP-9 are expressed strongly in gastric cancer tissue compared to normal tissue (17). Based on previous reports, although SLPI, MMP-2 and MMP-9 are involved directly in the metastatic process as an accelerating factor, the functions of these two molecules have not been reported.

This study examined whether SLPI promotes the cell migration and invasion related to MMP-2 and MMP-9 using two gastric cancer cell lines, SNU484 (no metastatic potential) and SNU638 (strong metastatic potential) (18). The results showed that SLPI promotes the metastatic process of SNU638 gastric cancer cells including cell migration and invasion by enhancing MMP-2 and MMP-9 expression through Elk-1 phosphorylation.

\section{Materials and methods}

Cell culture, SLPI-siRNA transfection. The gastric cancer cell line, SNU484 and SNU638, were purchased from Korean Cell Line Bank (KCLB, Republic of Korea). The cells (1x10 ${ }^{6}$ cells) were plated in 100-mm culture dishes and incubated in a $\mathrm{CO}_{2}$ incubator $\left(5 \% \mathrm{CO}_{2}, 37^{\circ} \mathrm{C}\right)$. The cells were then cultured in Dulbecco's modified Eagle's medium (DMEM) (Gibco-BRL, USA) supplemented with a $1 \%$ antibiotic-antimycotic solution (Gibco-BRL) containing 10\% fetal bovine serum (Gibco-BRL). The following sequences were used for the synthetic human SLPI-siRNA duplexes. The forward and reverse sequence of SLPI-siRNA was 5'-GAA GUG CCA GUU GAU CAA U-3' and 5'-AUU GAU CAA CUG GCA CUU C-3' (Bioneer, Republic of Korea), respectively. The SNU638 cells were subcultured in $60-\mathrm{mm}$ culture dishes $\left(1 \times 10^{5}\right.$ cells $)$ and transfected with 160 pmol SLPI-siRNA (si-SLPI/SNU638) using WellFect-si ${ }^{\mathrm{TM}}$ (WellGene, Republic of Korea). The si-SLPI/SNU638 cells were used for another experiment $72 \mathrm{~h}$ after transfection. The SNU484 and si-SLPI/SNU638 cells were incubated with a $1 \mu \mathrm{g} / \mathrm{ml}$ of recombinant human SLPI protein (rhSLPI; R\&D Systems, USA) (SNU484 + SLPI and si-SLPI/SNU638 + SLPI) for $24 \mathrm{~h}$ after serum starvation for $12 \mathrm{~h}$.

Extraction of total RNA and reverse transcription and polymerase chain reaction. The total RNA was extracted from the cells using the TRI reagent (MRC Inc., USA) according to the manufacturer's instruction. A sample of the total RNA $(1 \mu \mathrm{g})$ was used to synthesize the complementary DNA (cDNA). The synthesis of cDNA was performed on the AccuPower RT Premix (Bioneer). The PCR reaction was carried out in a thermal cycler (Takara, Japan) after adding $1 \mu \mathrm{l}$ of cDNA to the AccuPower PCR Premix (Bioneer). The following primers were synthesized
(Bioneer) for RT-PCR analysis: a) human SLPI: forward 5'-ACT CCT GCC TTC ACC ATG AA-3', reverse 5'-CAT TCG ATC AAC TGG CAC TT-3'; b) human MMP-2: forward 5'-TGA TGG TGT CTG CTG GAA AG-3', reverse 5'-GAC ACG TGA AAA GTG CCT TG-3'; c) human MMP-9: forward 5'-TGG GCT ACG TGA CCT ATG ACA T-3', reverse 5'-GCC CAG CCC ACC TCC ACT CCT C-3'; and d) glyceraldehyde 3-phosphate dehydrogenase (GAPDH): forward 5'-CCA TGG AGA AGG CTG GG-3' and reverse 5'-CAA AGT TGT CAT GGA TGA CC-3'. GAPDH was used as the internal control for RT-PCR. The PCR conditions for SLPI were as follows: initial denaturation for $5 \mathrm{~min}$ at $94^{\circ} \mathrm{C}$, followed by 29 cycles of denaturation at $94^{\circ} \mathrm{C}$ for $40 \mathrm{sec}$, annealing at $55^{\circ} \mathrm{C}$ for $40 \mathrm{sec}$ and extension at $72^{\circ} \mathrm{C}$ for $40 \mathrm{sec}$. The PCR conditions for MMP-2 were as follows: 4 min at $94^{\circ} \mathrm{C}$, 35 cycles at $94^{\circ} \mathrm{C}$ for $1 \mathrm{~min}, 1 \mathrm{~min}$ at $56^{\circ} \mathrm{C}, 1 \mathrm{~min}$ at $72^{\circ} \mathrm{C}$. MMP-9 were as follows: $5 \mathrm{~min}$ at $94^{\circ} \mathrm{C}, 30$ cycles at $94^{\circ} \mathrm{C}$ for $30 \mathrm{sec}, 30 \mathrm{sec}$ at $64^{\circ} \mathrm{C}, 30 \mathrm{sec}$ at $72^{\circ} \mathrm{C}$. The PCR conditions for GAPDH were as follows: $5 \mathrm{~min}$ at $94^{\circ} \mathrm{C}, 30$ cycles at $94^{\circ} \mathrm{C}$ for $30 \mathrm{sec}, 30 \mathrm{sec}$ at $56^{\circ} \mathrm{C}, 30 \mathrm{sec}$ at $72^{\circ} \mathrm{C}$. After the final cycle, all the samples were incubated for an additional $5 \mathrm{~min}$ at $72^{\circ} \mathrm{C}$. The products were electrophoresed on a $1.5 \%$ agarose gel buffered with $0.5 \mathrm{X}$ Tris-Borate-EDTA and stained with ethidium bromide after amplification. The staining bands were visualized by Gel-Doc (Bio-Rad Laboratories, USA). These primer sets recognized only the genes of interest, as indicated by the amplification of a single band of the expected size (570 bp for SLPI, $280 \mathrm{bp}$ for MMP-2, 172 bp for MMP-9 and 199 bp GAPDH) according to the nucleotide sequence of SLPI (Genbank no. NM_003064.2), MMP-2 (Genbank no. NM004530.4), MMP-9 (Genbank no. NM_004994.2) and GAPDH (Genbank no. M33197.1). The intensity of the bands was measured using a Science Lab Image Gauge (Fuji film, Japan).

Northern blotting. The total RNA (30 $\mu \mathrm{g})$ was electrophoresed on a $1.5 \%$ agarose gel buffered with $1 \mathrm{X}$ MOPS (0.02 M MOPS, $5 \mathrm{mM}$ sodium acetate, $1 \mathrm{mM}$ EDTA) supplemented with formaldehyde (Sigma, USA). The total RNA was transferred to a Hybond $\mathrm{N}^{+}$nylon membrane (Amershamphamacia, UK) for $12 \mathrm{~h}$ at room temperature after electrophoresis. The membrane was baked for $2 \mathrm{~min}$ and the total RNA was fixed for $90 \mathrm{sec}$ in a UV-cross-linker. The membrane was pre-hybridized in a hybridization solution ( $0.5 \%$ SDS, 6 X SSC, $10 \%$ dextran sulfate, $1 \mathrm{mM}$ EDTA) supplemented with $100 \mu \mathrm{g} / \mathrm{ml}$ of Salmon sperm DNA (Stratagene, CA) for $2 \mathrm{~h}$ at $62^{\circ} \mathrm{C}$. The SLPI and GAPDH PCR products were labeled with $\left[\alpha{ }^{32} \mathrm{P}\right]$-dCTP (AmershamPhamacia) as probes using a Random priming kit (AmershamPhamacia). The membrane was incubated in a hybridization solution with the $\left[\alpha{ }^{32} \mathrm{P}\right]$-dCTP labeled probe for $18 \mathrm{~h}$ at $60^{\circ} \mathrm{C}$. The membrane was washed twice with $2 \mathrm{X} \mathrm{SSC} / 0.1 \%$ SDS solutions (10 min, room temperature), once with the same solution $\left(30 \mathrm{~min}, 42^{\circ} \mathrm{C}\right)$ and once with a $0.1 \mathrm{X} \mathrm{SSC} / 0.1 \% \mathrm{SDS}$ solution $\left(30 \mathrm{~min}, 42^{\circ} \mathrm{C}\right.$ ). After washing, the membrane was exposed to X-ray film (Fuji film) for 48-72 $\mathrm{h}$ and developed in a dark room. The size of the SLPI and GAPDH bands was $0.7 \mathrm{~kb}$ and $1.5 \mathrm{~kb}$, respectively. The density and quantification of the expressed bands was measured using a Science Lab Image Gauge (Fuji film).

Western blotting. Western blotting was performed to examine the expression of the SLPI, MMP-2, MMP-9 and pElk-1 and $\beta$-actin proteins. The total cytosolic protein was extracted 
using an NP-40 lysis buffer [ $150 \mathrm{mM} \mathrm{NaCl}, 1 \% \mathrm{NP}-40,50 \mathrm{mM}$ Tris-Cl (pH 7.4), $2 \mathrm{mM} \mathrm{Na}_{3} \mathrm{VO}_{4}, 2 \mathrm{mM} \mathrm{Na}_{4} \mathrm{P}_{2} \mathrm{O}_{7}, 50 \mathrm{mM} \mathrm{NaF}, 2$ mM EDTA (pH 7.4) $0.1 \mu \mathrm{g} / \mathrm{ml}$ leupeptin and $1 \mu \mathrm{g} / \mathrm{ml}$ aprotinin]. These lysates were incubated on ice for $30 \mathrm{~min}$ and centrifuged at $13,000 \mathrm{rpm}$ and $4^{\circ} \mathrm{C}$. The nuclear protein was extracted from the cells using a Fraction PREP ${ }^{\mathrm{TM}}$ kit (BioVision, USA) according to the manufacturer's instructions. After protein extraction, the concentration in $30 \mu \mathrm{g}$ was determined using a Dc protein assay kit (Bio-Rad Laboratories). The quantity of secreted SLPI protein was examined by incubating the cells in the culture medium without serum for $18 \mathrm{~h}$. A $500-\mu \mathrm{l}$ sample of medium was mixed with $50 \mu \mathrm{l}$ of a protein $\mathrm{G}$ bead solution (Kirkegaard and Perry Laboratories, USA) and 1:100 of antirabbit SLPI (19) for $16 \mathrm{~h}$ at $4^{\circ} \mathrm{C}$. The bead-anti-SLPI complex was washed with 1X PBS and electrophoresed onto 10-15\% SDS polyacrylamide gel. After electrophoresis, the protein was transferred to a nitrocellulose membrane and blocked with either $5 \%$ non-fat dry milk or $5 \%$ bovine serum albumin (Sigma) for $1 \mathrm{~h}$ at room temperature. The membrane was blotted with 1:500 of anti-rabbit SLPI, 1:1,000 of anti-mouse MMP-2 (Millipore, USA), 1:2,000 of anti-rabbit MMP-9 (Millipore), 1:1,000 of anti-mouse phosphoElk-1 (pElk-1, Cell Signaling, USA) and $1: 2,500$ of anti-mouse $\beta$-actin (Sigma) for $16 \mathrm{~h}$ at $4^{\circ} \mathrm{C}$. After washing, the membrane was blotted with 1:5,000 - 1:10,000 of HRP-conjugated goat anti-rabbit or mouse-IgG (Santa Cruz Biotechnology, USA) and developed using chemiluminescence film (AmershamPhamacia) after being treated with an ECL solution (AmershamPhamacia). The size of the SLPI, MMP-2, MMP-9, pElk-1 and $\beta$-actin bands was $12 \mathrm{kDa}, 72 \mathrm{kDa}, 92 \mathrm{kDa}$, $62 \mathrm{kDa}$ and $42 \mathrm{kDa}$, respectively. The density of the expressed bands was measured using a Science Lab Image Gauge (Fuji film).

Migration and invasion assay. The SNU484, SNU638 and si-SLPI/SNU638 cells were incubated in serum-free medium for $18 \mathrm{~h}$ and detached from the culture plates using $0.25 \%$ TrypLE (Gibco-BRL). The cells were transferred to serumfree DMEM medium and suspended after centrifugation for $3 \mathrm{~min}$ at $12,000 \mathrm{rpm}$. For the migration assay, a HTS FluoroBlock ${ }^{\mathrm{TM}}$ Insert (BD Labware, USA) was placed onto a 24-well plate and $5 \times 10^{4}$ cells were added to the insert. The lower chambers of a 24-well plate were filled with $500 \mu \mathrm{l}$ serum-free DMEM with or without $1 \mu \mathrm{g} / \mathrm{ml}$ of rhSLPI, and the plate was incubated in a $\mathrm{CO}_{2}$ incubator $\left(5 \% \mathrm{CO}_{2}, 37^{\circ} \mathrm{C}\right)$ for 4 h. An invasion assay was performed with a BioCoat ${ }^{\mathrm{TM}}$ Tumor Invasion System (BD Labware) according to the manufacturer's instructions. The cells $\left(2.5 \times 10^{4}\right)$ were used in an invasion assay and the insert was coated with a basement membrane extract (BME). The lower chambers of the 24-well plate were filled with $750 \mu 1$ serum-free DMEM with or without $1 \mu \mathrm{g} / \mathrm{ml} \mathrm{rhSLPI}$ and the plate was incubated in a $\mathrm{CO}_{2}$ incubator $\left(5 \% \mathrm{CO}_{2}, 37^{\circ} \mathrm{C}\right)$ for $16 \mathrm{~h}$. The cells were stained with $1 \mathrm{X}$ PBS containing $4 \mu \mathrm{g} /$ $\mathrm{ml}$ Calcein-AM (Molecular Probe, USA) for $30 \mathrm{~min}$ at $37^{\circ} \mathrm{C}$ after migration or invasion. rhSLPI was not added to the lower chamber in the positive control (PC), and the negative control (NC) did not contain cells and rhSLPI in the insert and lower chamber, respectively. The fluorescence was measured using a GENios FL (wavelength excitation $485 \mathrm{~nm} / \mathrm{emission} 530 \mathrm{~nm}$, Tecan, Switzerland). The cells were observed by fluorescence microscopy (Olympus, Japan).
Gelatin zymography. The gelatin zymography was used to identify MMP-2 and MMP-9 secreted in the culture medium. The culture medium $(30 \mu \mathrm{l})$ of the SNU484, SNU484 + SLPI, SNU638, si-SLPI/SNU638, si-SLPI/SNU638 + SLPI and HT-1080 cells was electrophoresed on SDS 10\%-zymogram gel (Invitrogen, USA). The conditioned media from the HT-1080 human fibrosarcoma cells were loaded as a size marker for MMP-2 and MMP-9. After electrophoresis, the gels were incubated 3 times in a zymogram renaturing buffer (Invitrogen) at room temperature for $20 \mathrm{~min}$ and then in a zymogram developing buffer (Invitrogen) for $30 \mathrm{~min}$. The gels were then incubated at $37^{\circ} \mathrm{C}$ for $16 \mathrm{~h}$ after being transferred to the same developing buffer. After developing, the gels were stained with $0.2 \%$ Coomassie brilliant blue (Bio-Rad Laboratories) for $1 \mathrm{~h}$ and incubated with a destaining solution (10\% acetic acid, $40 \%$ methanol in distilled water) for $30 \mathrm{~min}$. The density of the MMP-2 and MMP-9 bands was measured using a Science Lab Image Gauge (Fuji film).

Statistical analysis. All experiments were performed at least in triplicate. All data are reported as the mean and standard deviation using Excel 2007 statistical software (Microsoft, USA). The significant differences $\left({ }^{*} \mathrm{p}<0.05,{ }^{* *} \mathrm{p}<0.005\right)$ were determined using a Student's t-test.

\section{Results}

Expression of SLPI mRNA and protein in SNU484 and SNU638 cells. RT-PCR showed that SLPI mRNA was expressed strongly in SNU638 cells; 54 times higher than that observed in the SNU484 cells $(\mathrm{p}<0.005)$ (Fig. 1A). SLPI mRNA expression was detected at very low levels in the SNU484 cells by Northern blotting but was expressed strongly in SNU638 cells; 133 times higher than that observed in the SNU484 cells $(\mathrm{p}<0.005)$ (Fig. 1B). The secreted SLPI protein was not detected in the medium of the SNU484 cells and was enhanced 80 -fold in the SNU638 cells compared to the SNU484 cells. The SLPI protein was expressed strongly in the SNU638 cells; 108 times higher than that observed in the SNU484 cells $(\mathrm{p}<0.005)$ (Fig. 1C).

Migration and invasion in SNU484 and SNU638 cells after the SLPI treatment. The migration assay showed that the fluorescence intensity of SNU638 cells was 1.7 times higher than that of SNU484 cells (PC). After the SLPI treatment, the fluorescence intensity was 1.7 times higher in the SNU484 cells than the SNU484 cells (PC), and 1.5 times higher in the SNU638 cells than the SNU638 (PC) $(\mathrm{p}<0.05)$ (Fig. 2A). Fluorescence microscopy revealed many migrated SNU638 cells than SNU484 cells (PC). The SLPI treatment increased the migration of both cell types compared to the PC (Fig. 2B). In the invasion assay, the fluorescence intensity of the SNU638 cells was 4.2 times higher than that in the SNU484 cells (PC). After the SLPI treatment, the fluorescence intensity of the SNU484 cells was increased 3 -fold $(\mathrm{p}<0.05)$ compared to the SNU484 (PC) but the SNU638 cells was unchanged (Fig. 2C). Fluorescence microscopy revealed a higher number of invading SNU638 cells than SNU484 cells (PC). After the SLPI treatment, the invasion of SNU484 cells was higher than that of SNU484 (PC) but the SNU638 cells showed a similar level of invasion to SNU638 (PC) (Fig. 2D). The rate of SNU484 and 
A

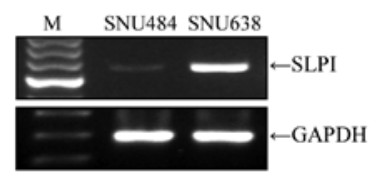

B

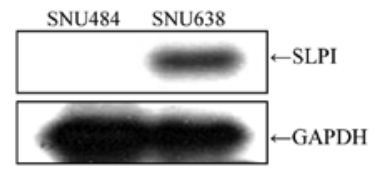

C

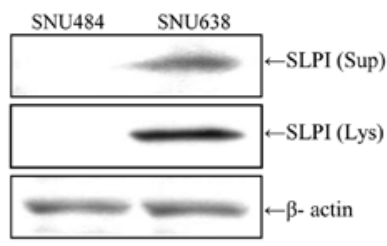

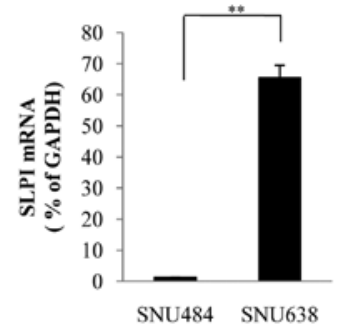
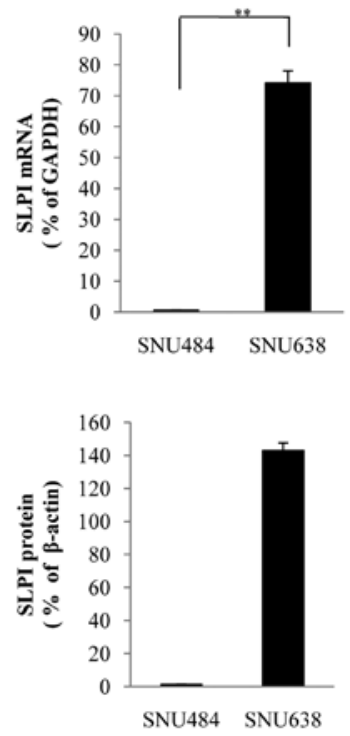

Figure 1. SLPI mRNA and protein expression in SNU484 and SNU638 cells. SLPI mRNA expression in SNU484 and SNU638 cells was compared using RT-PCR (A) and Northern blotting (B). SLPI mRNA was expressed strongly in SNU638 cells compared to SNU484 cells. (C), The expression of secreted and cytosolic SLPI protein in SNU484 and SNU638 cells was compared. The secreted and cytosolic SLPI protein was expressed strongly in SNU638 cells compared to SNU484 cells. $\beta$-actin was used as the internal control. Sup, supernatant; Lys, lysate.

SNU638 cell migration was higher than the invasion rate of the PC and SLPI-treated group (Fig. 2A and C).

Invasion of SNU638 cells after transfection of SLPI siRNA. SLPI mRNA was expressed 54 and 56 times more strongly in the SNU638 cells than in the SNU484 and si-SLPI/SNU638 cells, respectively $(\mathrm{p}<0.005)$ (Fig. 3A). In addition, the level of SLPI protein expression was 15 and 24 times higher in the SNU638 cells than in the SNU484 and si-SLPI/SNU638 cells, respectively $(\mathrm{p}<0.005)$ (Fig. $3 \mathrm{~B})$. In the invasion assay, the fluorescence intensity was 4.4 and 5.2 times higher in the SNU638 cells than in the SNU484 and si-SLPI/SNU638 cells, respectively $(\mathrm{p}<0.005)$ (Fig. 3C). Fluorescence microscopy revealed significantly less si-SLPI/SNU638 cell invasion than the SNU638 cells (Fig. 3D).

The expression of MMP-2, MMP-9 and pElk-1 on SLPI and si-SLPI-treated cells. The level of MMP-2 and MMP-9 mRNA expression was 2.3 and 5.2 times higher in the SNU484 + SLPI cells than SNU484 cells $(\mathrm{p}<0.05)$ but was 5.6 and 4.3 times higher in the SNU638 cells than si-SLPI/SNU638 cells, respectively ( $\mathrm{p}<0.005)$. In si-SLPI/SNU638 + SLPI cells, MMP-2 mRNA expression was 1.9 times higher but MMP-9 expression

was 1.6 times lower than in the si-SLPI/SNU638 cells. In addition, the level of MMP-2 and MMP-9 mRNA expression was 3.9 and 14 times higher in the SNU638 cells than SNU484 cells, respectively (Fig. 4A). Zymography revealed a 55- and 23-fold increase in MMP-2 and MMP-9 protein secretion in SNU484 + SLPI cells than SNU484 cells, and a 4.0- and 4.4-fold decrease in the si-SLPI/SNU638 cells compared to the SNU638 cells $(\mathrm{p}<0.005)$. MMP-2 and MMP-9 protein secretion was 2.0 and 2.3 times higher in the si-SLPI/SNU638 + SLPI cells than si-SLPI/SNU638 cells. In addition, the level of MMP-2 and MMP-9 protein secretion was 70 and 36 times higher in the SNU638 cells than SNU484 cells, respectively (Fig. 4B).

The expression of the MMP-2 and MMP-9 protein was 2.5 and 2.9 times higher in the SNU484 + SLPI cells than SNU484 cells, respectively $(\mathrm{p}<0.05)$ but was 4.6 and 10.2 times higher in the SNU638 cells than si-SLPI/SNU638 cells, respectively $(\mathrm{p}<0.005)$. The level of MMP-9 protein expression was similar in the si-SLPI/SNU638 and si-SLPI/SNU638 + SLPI cells but the level of MMP-2 was 3.2 times higher in the si-SLPI/ SNU638 + SLPI cells than si-SLPI/SNU638 cells. The expression of the MMP-2 and MMP-9 protein was 4.6 and 10.4 times higher in the SNU638 cells than SNU484, respectively (Fig. 5). The expression of pElk-1 was barely detectable in the SNU484 cells but was expressed strongly in the SNU484 + SLPI cells; 46 times higher than that observed in the SNU484 cells $(\mathrm{p}<0.005)$. On the other hand, the level of pElk-1 protein expression in si-SLPI/SNU638 cells decreased to a similar level to that observed in SNU484 cells ( $\mathrm{p}<0.005)$. The pElk-1 expression was 18.4 times higher in si-SLPI/SNU638 + SLPI cells than si-SLPI/SNU638 cells, and 61 times higher in SNU638 cells than SNU484 cells (Fig. 5).

\section{Discussion}

SLPI is expressed in a range of cancer cell lines, and is particularly overexpressed in the highly liver metastatic tumor cell line, IMC-HA1 (20). SLPI is overexpressed in rarely developed inflammatory breast cancer with highly angiogenic and metastatic capacity (21). In addition, the overexpression of SLPI in lung carcinoma cells showed rapid tumorigenicity and lung metastasis upon subcutaneous inoculation compared to the control cells (7). The level of SLPI expression was higher in all types of ovarian cancers. Moreover, the blood concentration of SLPI is high in ovarian cancer compared to normal ovaries or benign ovarian tumors, and is particularly high in malignant tumors with a high metastatic potential (22). SLPI mRNA is overexpressed in serosa invading gastric cancer cells, and the cell migration and invasion rate was significantly increased in AZ521 cells, a SLPI overexpressing gastric cancer cell line (16). In the present study, SLPI mRNA and protein expression in SNU638 cells, which have higher metastatic potential than SNU484 cells, was higher than in SNU484 cells. In addition, the migration and invasion rate of SNU638 cells was higher than that in SNU484 cells. After treatment with the SLPI protein, the migration rate was higher in both cell types, and the invasion rate was higher in the SNU484 cells than SNU638 cells under these conditions. However, the invasion rate was significantly lower in the si-SLPI/SNU638 cells. Furthermore, the migration and invasion rate of non-metastatic SNU484 cells after the SLPI treatment was similar to that in SNU638 cells. 
A

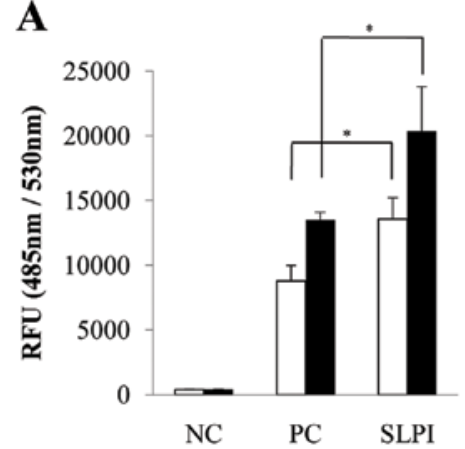

C

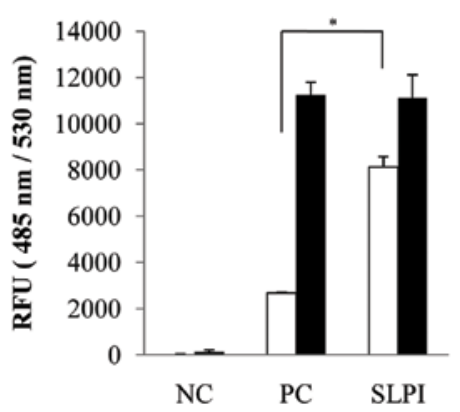

B

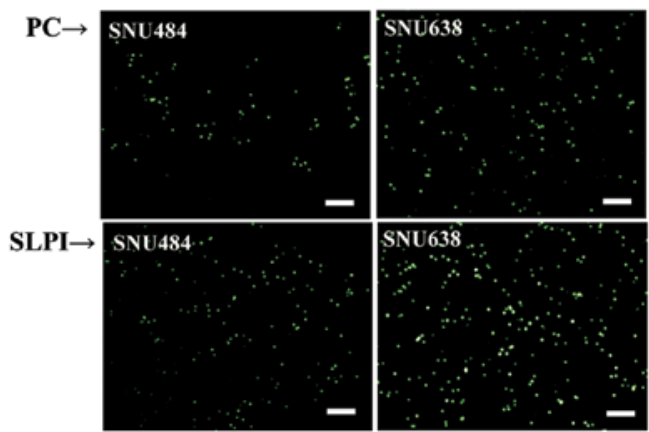

D

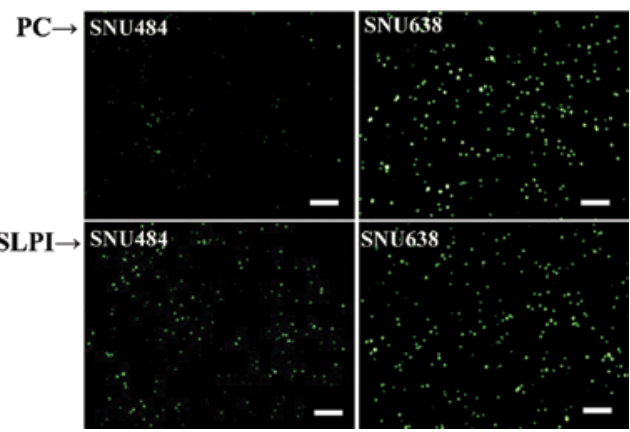

Figure 2. Migration and invasion by SLPI in SNU484 and SNU638 cells. A migration (A) and invasion (C) of SNU638 cells was higher than in the positive control (PC) SNU484 cells. The migration of SNU484 and SNU638 cells was higher than the PC after the SLPI treatment. The invasion of SNU484 cells was increased but the SNU638 cells were unaffected compared to the PC of SNU638 cells after the SLPI treatment. More migrated (B) and invaded (D) cells were observed in SNU638 than SNU484 cells. RFU, relative fluorescent units; NC, negative control. All scale bars are $200 \mu \mathrm{m}$.

A

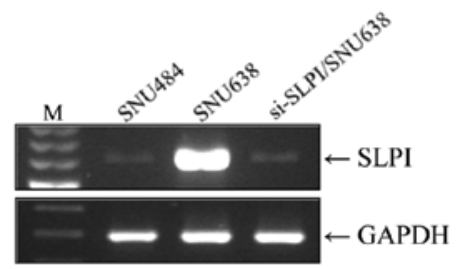

B

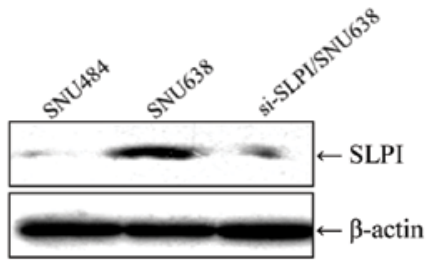

C

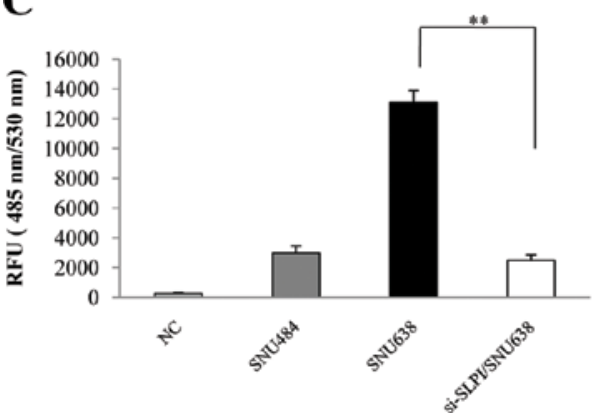

D
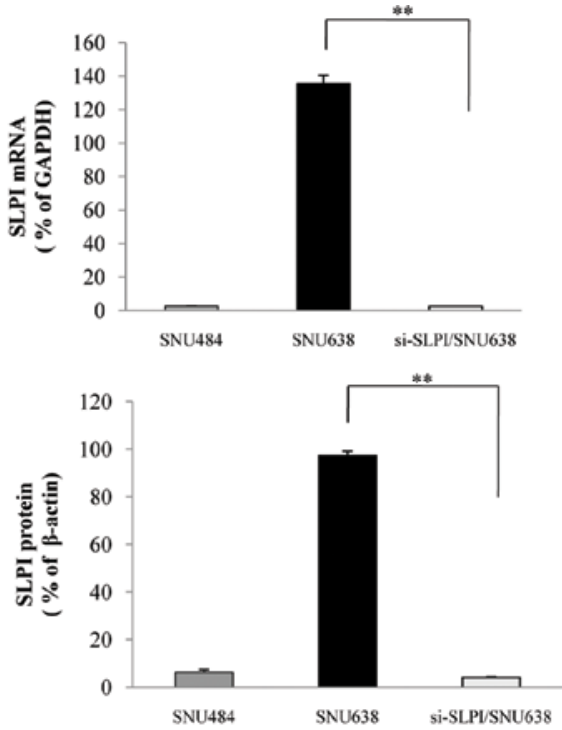

Figure 3. SLPI mRNA, protein expression and invasion assay in SNU484, SNU638 and si-SLPI/SNU638 cells. (A), The expression of SLPI mRNA was significantly lower in si-SLPI/SNU638 cells than in SNU638 cells. (B), The level of SLPI protein expression was significantly higher in si-SLPI/SNU638 cells in accordance with the mRNA expression. (C and D), Invasion assay of SNU484, SNU638 and si-SLPI/SNU638 cells. The number of invaded si-SLPI/SNU638 cells was significantly lower than SNU638 cells. All scale bars are $200 \mu \mathrm{m}$. 

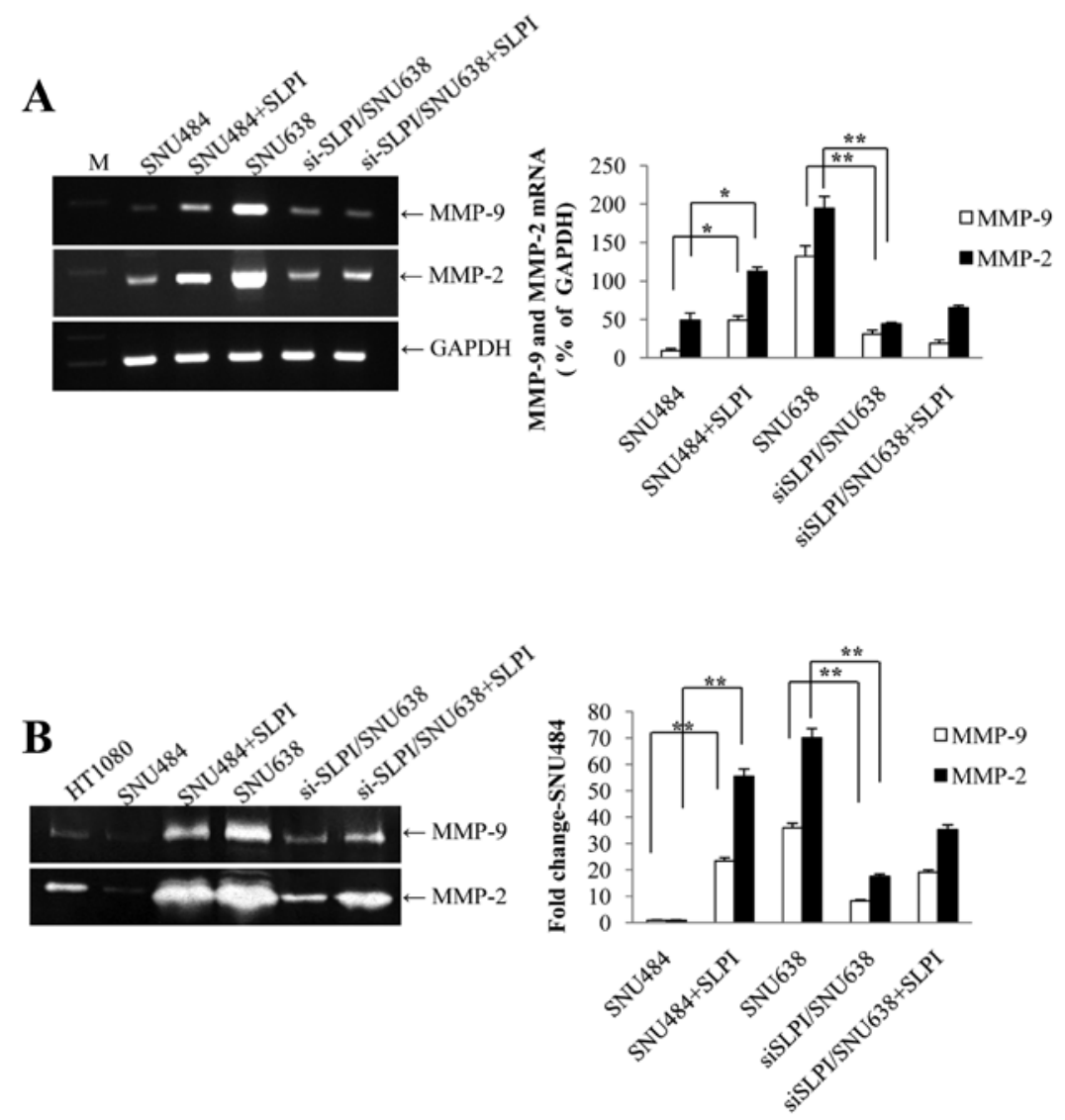

Figure 4. Expression of MMP-2 and MMP-9 in SNU484, SNU484 + SLPI, SNU638, si-SLPI/SNU638 and si-SLPI/SNU638 + SLPI cells. (A), The level of MMP-2 and MMP-9 mRNA expression was higher in SNU484 + SLPI cells than the SNU484 cells but was lower in si-SLPI/SNU638 cells than in SNU638 cells. (B), MMP-2 and MMP-9 secretion in SNU cells using gelatin zymography. The quantity of MMP-2 and MMP-9 secreted was significantly higher in SNU484 + SLPI cells than SNU484 cells but was lower in si-SLPI/SNU638 and si-SLPI/SNU638 + SLPI cells than in SNU638 cells.
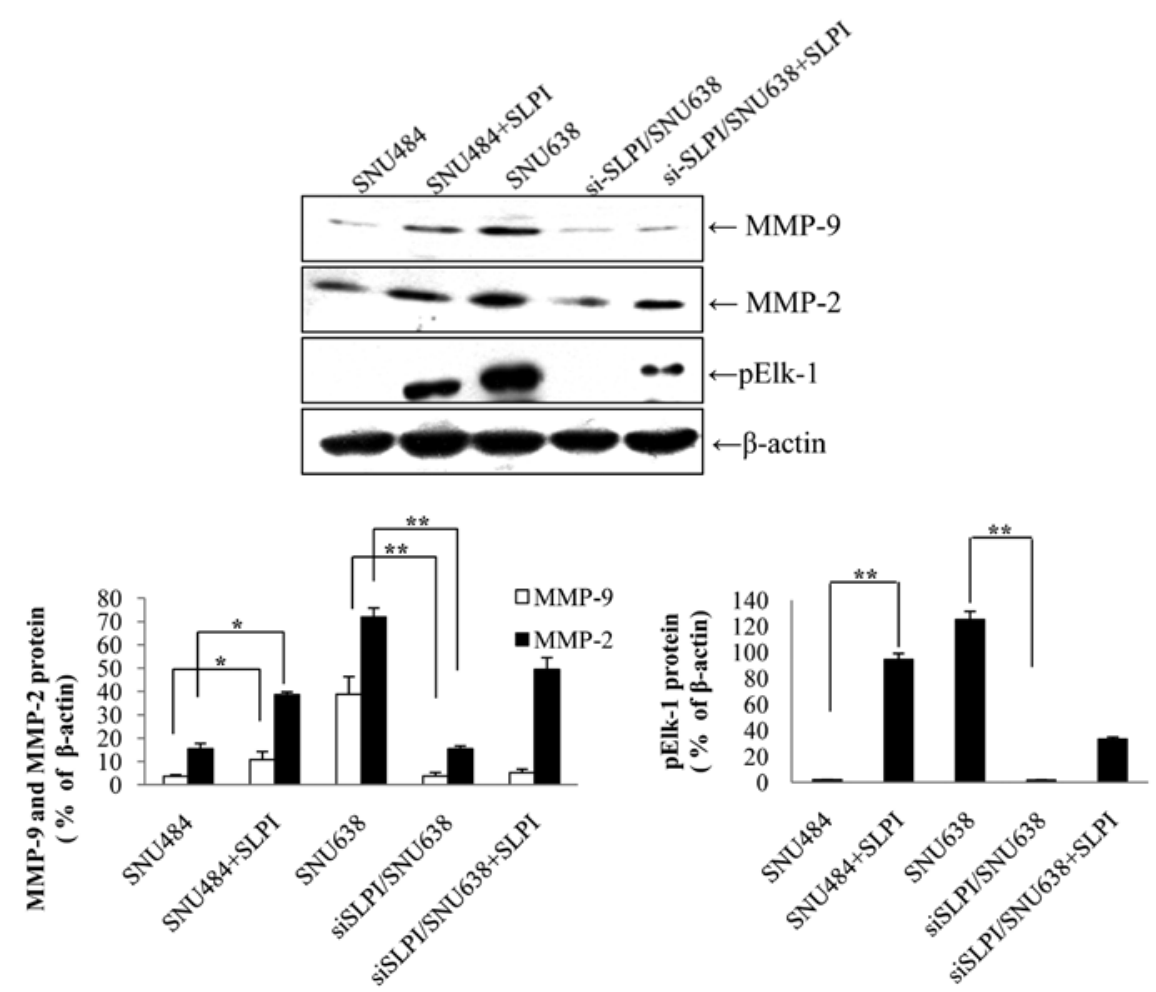

Figure 5. MMP-2 and MMP-9 expression related to the phosphorylation of pElk-1 in SNU484, SNU484 + SLPI, SNU638, si-SLPI/SNU638 and si-SLPI/SNU638 + SLPI cells. Expression of MMP-2, MMP-9 and Elk-1 proteins was significantly higher in SNU484 + SLPI and SNU638 cells than in SNU484 cells but the levels of these proteins were lower in si-SLPI/SNU638 cells than in SNU638 cells. 
This suggests that SLPI accelerates the migration and invasion of SNU638 gastric cancer cells, as in other cancer cells.

Matrix metalloproteinases (MMPs) are responsible for reorganizing the extracellular matrix as enzymes under physiological and pathological circumstances. Degradation of the extracellular matrix by MMP in cancer progression is one of the processes for angiogenesis, cell migration, invasion and metastasis, and the balance of expression and activation between the MMPs and protease inhibitors is very important in these processes. Among these MMPs, the expression and activation of MMP-2 and MMP-9 was higher in malignant lung cancer than normal tissue (23). In addition, the expression of MMP-2 and MMP-9 was higher in malignant ovarian cancer, which promoted lymphatic metastasis (24). A high circulating blood concentration of MMP-2 and MMP-9 and enhanced metastatic potential of cancer cells were observed in a gastric cancer patient (25). Moreover, the level of MMP-2 and MMP-9 was higher in malignant gastric cancer tissue, and MMP-2 plays a key role for the spreading of gastric carcinoma cells (26). In this study, the MMP-2 and MMP-9 mRNA and protein was expressed strongly in SNU638 cells and secreted abundantly to the extracellular space. Interestingly, MMP-2 expression was higher than MMP-9. In a previous study, MMP-2 protein expression was higher in endometrioid carcinoma tissue than MMP-9 (27), and MMP-2 plasma level was higher than MMP-9 in ovarian tumor tissue (28). In contrast, MMP-9 protein expression was higher than MMP-2 in ameloblastoma and adenomatoid odontogenic tumors (29). In addition, the number of MMP-9 positive cells and plasma level were significantly higher than that of MMP-2 in melanoma tissue (30). A level of MMP-9 protein and mRNA was significantly higher in gastric cancer tissue that MMP-2 $(17,31)$. The reason for the differences in the expression and activity of MMP-2 and MMP-9 is unknown but might be due to the matrix-matrix interactions with cancer cells (32).

The SLPI protein is divided into two domains, to act as an anti-inflammatory cytokine and to inhibit protease (2). As an anti-inflammatory cytokine, SLPI decreased the inflammatory response in the conjunctiva with the viral antigen to suppress the infiltration and degranulation of eosinophil (33). In addition, SLPI decreased the tissue injury via the inflammatory response in arthritis as the reducing infiltration of neutrophils (34). As a protease inhibitor, SLPI protected against injuries to the human bronchial tissue through an inflammatory response by inhibiting the elastase activity secreted from neutrophils (4). Although tissue inhibitor of matrix metalloproteinases (TIMP) inhibits MMPs, the mRNA expression of TIMP-1, TIMP-2, MMP-2 and MMP-9 was higher in breast cancer tissue and the metastasis was high in the lymph nodes or other organs (35). In the present study, RT-PCR, zymography and Western blot results showed that SLPI regulates the level of MMP-2 and MMP-9 expression.

The level of MMP-2 and MMP-9 secretion is higher in the skin wounds of SLPI null mice compared to the wild-type (15). Moreover, MMP-9 expression was increased during the inflammatory response in bronchiole epithelial cells but decreased significantly after SLPI treatment (36). Based on previous reports, exogenous SLPI may suppress the expression and secretion of MMP-9 in the inflammatory response by treatment with LPS or wound induction. Interestingly, SLPI, MMP-2 and MMP-9 are expressed strongly and secreted in high metastatic SNU638 cells but not in si-SLPI/SNU638 cells. In addition, the rate of si-SLPI/SNU638 cell invasion was found to be significantly lower than that of SNU638 cells. MMP-9 secretion was increased significantly by LPS stimulation but this increase in secretion was interrupted by SLPI treatment, suggesting that SLPI acts as a signaling molecule, which is not a protease inhibitor in monocytes (14). Hepatocyte growth factor (HGF) increased the rate of invasion, Elk-1 phosphorylation (pElk-1) and MMP-9 secretion in the human hepatoma cell line, HepG2 (37). Elk-1 is a transcription factor known to induce the expression of the MMP-2 and MMP-9 gene by binding to the promoter region of the MMP-2 and MMP-9 gene after phosphorylation $(38,39)$. Therefore, SLPI-siRNA was transfected to SNU638 cells to regulate MMP-2 and MMP-9 by SLPI. In addition, SNU484 and si-SLPI/SNU638 cells were treated with the rhSLPI protein. These results showed that MMP-2 and MMP-9 are expressed weakly in SNU484 cells but strongly in SNU484 + SLPI and SNU638 cells, and were significantly lower in si-SLPI/SNU638 cells. pElk-1 was barely detectable in SNU484 cells but was expressed strongly in SNU484 + SLPI and SNU638 cells. The level in si-SLPI/SNU638 cells was similar to that observed in SNU484 cells. In addition, the expression pattern of pElk-1 was similar to the expression and secretion of MMP-2 and MMP-9 in these cells. These results suggest that SLPI can regulate the increase in MMP-2 and MMP-9 expression by inducing Elk-1 phosphorylation.

In conclusion, SLPI may play a role not as protease inhibitor but as a signaling molecule, promoting the metastatic process including cell migration and the invasion of gastric cancer cells, SNU638, by increasing MMP-2 and MMP-9 expression through Elk-1 phosphorylation. Nevertheless, a further examination of the signaling transduction pathway of SLPI in MMP-2 and MMP-9 expression will be needed.

\section{Acknowledgements}

This work was supported by the National Research Foundation of Korea (NRF) funded by the Ministry of Education, Science and Technology (No. R13-2008-010-00000-0).

\section{References}

1. Schwartz GK: Invasion and metastases in gastric cancer: in vitro and in vivo models with clinical correlations. Semin Oncol 23: 316-324, 1996.

2. Thompson RC and Ohlsson K: Isolation, properties, and complete amino acid sequence of human secretory leukocyte protease inhibitor, a potent inhibitor of leukocyte elastase. Proc Natl Acad Sci USA 83: 6692-6696, 1986.

3. Choi BD, Jeong SJ, Wang G, Kim HJ, Kim BO, Hwang HK, Lim DS, Kim SH and Jeong MJ: Temporal induction of secretory leukocyte protease inhibitor (SLPI) in odontoblasts by lipopolysaccharide and wound infection. J Endod 35: 997-1002, 2009.

4. McElvaney NG and Taggart CC: Chronic obstructive pulmonary disease: cellular and molecular mechanisms. Taylor and Francis. Barnes P (ed). Boca Raton, pp343-365, 2005.

5. Shugars DC and Wahl SM: The role of the oral environment in HIV-1 transmission. J Am Dent Assoc 129: 851-858, 1998.

6. Sallenave JM: Antimicrobial activity of antiproteinases. Biochem Soc Trans 30: 111-115, 2002.

7. Devoogdt N, Revets H, Ghassabeh GH and De Baetselier P: Secretory leukocyte protease inhibitor in cancer development. Ann NY Acad Sci 1028: 380-389, 2004.

8. Wang G, Lim DS, Choi BD, Park JJ, Jeong SJ, Kim JS, Kim JD, Park JS, Kim EK, Kim BH, Ham JH and Jeong MJ: Effect of secretory leukocyte protease inhibitor on migration and invasion of human KB oral carcinoma cells. Animal Cells and Systems (In press). 
9. Liotta LA, Tryggvason K, Garbis S, Hart I, Foltz CM and Shafie S Metastatic potential correlates with enzymatic degradation of basement membrane collagen. Nature 284: 67-68, 1980.

10. Egeblad M and Werb Z: New functions for the matrix metalloproteinases in cancer progression. Nat Rev Cancer 2: 161-174, 2002

11. Xu J, Rodriguez D, Petitclerc E, Kim JJ, Hangai M, Moon YS, Davis GE and Brooks PC: Proteolytic exposure of a cryptic site within collagen type IV is required for angiogenesis and tumor growth in vivo. J Cell Biol 154: 1069-1079, 2001.

12. Kim J, Yu W, Kovalski K and Ossowski L: Requirement for specific proteases in cancer cell intravasation as revealed by a novel semiquantitative PCR-based assay. Cell 94: 353-362, 1998.

13. Hua $\mathbf{J}$ and Muschel RJ: Inhibition of matrix metalloproteinase 9 expression by a ribozyme blocks metastasis in a rat sarcoma model system. Cancer Res 56: 5279-5284, 1996.

14. Zhang Y, De Witt DL, McNeely TB, Wahl SM and Wahl LM Secretory leukocyte protease inhibitor suppresses the production of monocyte prostaglandin $\mathrm{H}$ synthase-2, prostaglandin E2, and matrix metalloproteinases. J Clin Invest 99: 894-900, 1997.

15. Angelov N, Moutsopoulos N, Jeong MJ, Nares S, Ashcroft G and Wahl SM: Aberrant mucosal wound repair in the absence of secretory leukocyte protease inhibitor. Thromb Haemost 92 : 288-297, 2004

16. Cheng WL, Wang CS, Huang YH, Liang Y, Lin PY, Hsueh C, Wu YC, Chen WJ, Yu CJ, Lin SR and Lin KH: Overexpression of a secretory leukocyte protease inhibitor in human gastric cancer. Int J Cancer 123: 1787-1796, 2008.

17. Sier CF, Kubben FJ, Ganesh S, Heerding MM, Griffioen G, Hanemaaijer R, van Krieken JH, Lamers CB and Verspaget HW: Tissue levels of matrix metalloproteinases MMP-2 and MMP-9 are related to the overall survival of patients with gastric carcinoma. Br J Cancer 74: 413-417, 1996.

18. Park JG, Yang HK, Kim WH, Chung JK, Kang MS, Lee JH, Oh JH, Park HS, Yeo KS, Kang SH, Song SY, Kang YK, Bang YJ, Kim YH and Kim JP: Establishment and characterization of human gastric carcinoma cell lines. Int J Cancer 70: 443-449, 1997.

19. Choi BD, Lee SH, Jeong SJ, Jang HS, Kim BO, Lim DS, Park JC, Wang $\mathrm{G}$ and Jeong MJ: Increased protein of the secretory leukocyte protease inhibitor (SLPI) and expression of growth factors in NIH3T3 cells by LPS stimulation. Korean J Electron Microscopy 36: 165-172, 2006.

20. Morita $\mathrm{M}$, Arakawa $\mathrm{H}$ and Nishimura S: Identification and cloning of a novel isoform of mouse secretory leukocyte protease inhibitor, mSLPI- $\beta$, overexpressed in murine leukemias and a highly liver metastatic tumor, IMC-HA1 cells. Adv Enzyme Regul 33: 341-355, 1999.

21. Bertucci F, Finetti P, Rougemont J, Charafe-Jauffret E, Nasser V, Loriod B, Camerlo J, Tagett R, Tarpin C, Houvenaeghel G, Nguyen C, Maraninchi D, Jacquemier J, Houlgatte R, Birnbaum D and Viens P: Gene expression profiling for molecular characterization of inflammatory breast cancer and prediction of response to chemotherapy. Cancer Res 64: 8558-8565, 2004.

22. Tsukishiro S, Suzumori N, Nishikawa H, Arakawa A and Suzumori K: Use of serum secretory leukocyte protease inhibitor levels in patients to improve specificity of ovarian cancer diagnosis. Gynecol Oncol 96: 516-519, 2005.

23. Nawrocki B, Polette M, Marchand V, Monteau M, Gillery P, Tournier JM and Birembaut P: Expression of matrix metalloproteinases and their inhibitors in human bronchopulmonary carcinomas: quantificative and morphological analyses. Int $\mathbf{J}$ Cancer 72: 556-564, 1997.

24. Sakata K, Shigemasa K, Nagai N and Ohama K: Expression of matrix metalloproteinases (MMP-2, MMP-9, MT1-MMP) and their inhibitors (TIMP-1, TIMP-2) in common epithelial tumors of the ovary. Int J Oncol 17: 673-681, 2000.
25. Endo K, Maehara Y, Baba H, Yamamoto M, Tomisaki S, Watanabe A, Kakeji Y and Sugimachi K: Elevated levels of serum and plasma metalloproteinases in patients with gastric cancer. Anticancer Res 17: 2253-2258, 1997.

26. Nomura H, Fujimoto N, Seiki M, Mai M and Okada Y: Enhanced production of matrix metalloproteinases and activation of matrix metalloproteinase 2 (gelatinase A) in human gastric carcinomas. Int J Cancer 69: 9-16, 1996.

27. Shaco-Levy R, Sharabi S, Piura B and Sion-Vardy N: MMP-2, TIMP-1, E-cadherin, and beta-catenin expression in endometrial serous carcinoma compared with low-grade endometrial endometrioid carcinoma and proliferative endometrium. Acta Obstet Gynecol Scand 87: 868-874, 2008.

28. Määtta $M$, Talvensaari-Mattila $\mathrm{A}$, Turpeenniemi-Hujanen $\mathrm{T}$ and Santala M: Matrix metalloproteinase-2 (MMP-2) and -9 (MMP-9) and their tissue inhibitors (TIMP-1 and TIMP-2) in differential diagnosis between low malignant potential (LMP) and malignant ovarian tumours. Anticancer Res 27: 2753-2758, 2007.

29. Ribeiro BF, Iglesias DP, Nascimento GJ, Galvão HC, Medeiros AM and Freitas RA: Immunoexpression of MMPs-1, -2 , and -9 in ameloblastoma and odontogenic adenomatoid tumor. Oral Dis 15: 472-477, 2009

30. Redondo P, Lloret $\mathrm{P}$, Idoate $\mathrm{M}$ and Inoges $\mathrm{S}$ : Expression and serum levels of MMP-2 and MMP-9 during human melanoma progression. Clin Exp Dermatol 30: 541-545, 2005.

31. Sampieri CL, De la Peña S, Ochoa-Lara M, Zenteno-Cuevas R and León-Córdoba K: Expression of matrix metalloproteinases 2 and 9 in human gastric cancer and superficial gastritis. World $\mathbf{J}$ Gastroenterol 16: 1500-1505, 2010.

32. Väisänen AH, Kallioinen $M$ and Turpeenniemi-Hujanen T: Comparison of the prognostic value of matrix metalloproteinases 2 and 9 in cutaneous melanoma. Hum Pathol 39: 377-385, 2008.

33. Murata E, Sharmin S, Shiota H, Shiota M, Yano M and Kido H: The effect of topically applied secretory leukocyte protease inhibitor on the eosinophil response in the late phase of allergic conjunctivitis. Curr Eye Res 26: 271-276, 2003.

34. Sehnert B, Cavcic A, Böhm B, Kalden JR, Nandakumar KS Holmdahl R and Burkhardt H: Antileukoproteinase: modulation of neutrophil function and therapeutic effects on anti-type II collagen antibody-induced arthritis. Arthritis Rheum 50: 2347-2359, 2004.

35. Ree AH, Florenes VA, Berg JP, Maelandsmo GM, Nesland JM and Fodstad O: High levels of messenger RNAs for tissue inhibitors of metalloproteinases (TIMP-1 and TIMP-2) in primary breast carcinomas are associated with development of distant metastases. Clin Cancer Res 3: 1623-1628, 1997.

36. Qu MY, Luo BL, Chen HM, Feng JT and Gu QH: Effects of secretory leukocyte protease inhibitor on expression of inflammation mediators in normal human bronchial epithelial cells induced by cigarette smoke extract. Zhonghua Jie $\mathrm{He} \mathrm{He} \mathrm{Hu} \mathrm{Xi}$ Za Zhi 31: 352-355, 2008

37. Abiru S, Nakao K, Ichikawa T, Migita K, Shigeno M, Sakamoto M, Ishikawa H, Hamasaki K, Nakata $K$ and Eguchi K: Aspirin and NS-398 inhibit hepatocyte growth factor-induced invasiveness of human hepatoma cells. Hepatology 35: 1117-1124, 2002.

38. Hsieh HL, Wu CY and Yang CM: Bradykinin induces matrix metalloproteinase-9 expression and cell migration through a PKC-delta-dependent ERK/Elk-1 pathway in astrocytes. Glia 56: 619-632, 2008

39. Mahmoodzadeh S, Dworatzek E, Fritschka S, Pham TH and Regitz-Zagrosek V: 17beta-estradiol inhibits matrix metalloproteinase-2 transcription via MAP kinase in fibroblasts. Cardiovasc Res 85: 719-728, 2010. 